Old Dominion University

ODU Digital Commons

VMASC Publications

Virginia Modeling, Analysis \& Simulation Center

2012

\title{
Evacuee Route Choice Decisions in a Dynamic Hurricane Evacuation Context
}

\author{
R. Michael Robinson \\ Old Dominion University,rmrobins@odu.edu
}

Asad Khattak

Old Dominion University

Follow this and additional works at: https://digitalcommons.odu.edu/vmasc_pubs

Part of the Civil Engineering Commons, Emergency and Disaster Management Commons, Transportation Commons, and the Transportation Engineering Commons

\section{Repository Citation}

Robinson, R. Michael and Khattak, Asad, "Evacuee Route Choice Decisions in a Dynamic Hurricane Evacuation Context" (2012). VMASC Publications. 29.

https://digitalcommons.odu.edu/vmasc_pubs/29

\section{Original Publication Citation}

Robinson, R. M., \& Khattak, A. (2012). Evacuee route choice decisions in a dynamic hurricane evacuation context. Transportation Research Record, 2312, 141-149. doi:10.3141/2312-15

This Article is brought to you for free and open access by the Virginia Modeling, Analysis \& Simulation Center at ODU Digital Commons. It has been accepted for inclusion in VMASC Publications by an authorized administrator of ODU Digital Commons. For more information, please contact digitalcommons@odu.edu. 


\title{
Evacuee Route Choice Decisions in a Dynamic Hurricane Evacuation Context
}

\author{
R. Michael Robinson and Asad Khattak
}

Very high traffic volumes may lead to extensive congestion during hurricane evacuations. Evacuation planners reduce this congestion by careful planning for multiple hurricane scenarios and assignment of evacuation routes and timing. This planning may be for naught if obstructions block key roadways. An advanced traveler information system (ATIS) may be used to guide evacuees to alternate routes, but how effective will that guidance be? Should the use of alternate routes be encouraged? How are drivers likely to respond to delays and information? Will information shorten or improve the reliability of travel times in emergency conditions? Integration of a dynamic evacuation simulation and a decision-making model (representative of the decisions made by potential hurricane evacuees when provided with information on downstream traffic congestion and alternate routes) can help emergency planners prepare for the unexpected. Advance modeling of likely accident locations and the severity can forecast the effects of alternate route use, help determine the best locations and timing of alternate route information, and support decision making. This study integrated an evacuee route choice decision model and a mesoscopic evacuation transportation simulation for southeastern Virginia. Study results show how the effects of ATIS can be tested in advance, thus allowing more comprehensive planning by emergency management and transportation professionals. Simulations of ATIS' effectiveness in evacuation scenarios have been largely unexplored. Methods presented can be applied in a variety of evacuation scenarios and may be of particular value to emergency planners.

The massive traffic jams that occurred before past hurricanes show what can happen when an evacuation goes awry. Many Florida evacuees for Hurricane Floyd reported travel times of greater than $24 \mathrm{~h}$. The evacuation from Charleston, South Carolina, for Hurricane Floyd required an average of more than $9 \mathrm{~h}$, with almost $60 \%$ of evacuees reporting that the evacuation took more than $5 \mathrm{~h}$ longer than expected (1). Many Texas evacuees for Hurricane Rita were stuck in traffic jams for more than $10 \mathrm{~h}$ (2). Extended travel times exposed evacuees to dangers potentially even greater than those faced had they remained at home.

Evacuation plans were in place for the regions affected by these storms, but plans did not match the reality experienced because unexpected events thwarted the plan. Unfortunately, in a hurricane

R. M. Robinson, Virginia Modeling, Analysis, and Simulation Center, 1030 University Boulevard, Old Dominion University, Suffolk, VA 23435. A. Khattak, Civil and Environmental Engineering Department, Old Dominion University, 135 Kaufman Hall, Norfolk, VA 23529. Corresponding author: R. M. Robinson, RMRobins@ odu.edu.

Transportation Research Record: Journal of the Transportation Research Board, No. 2312, Transportation Research Board of the National Academies, Washington, D.C., 2012, pp. 141-149.

DOI: $10.3141 / 2312-15$ evacuation, unexpected events must be the expected condition. Traffic incidents may block evacuation routes. Evacuees may depart at rates significantly different from those expected. Storm debris or road construction may reduce traffic flows at critical points.

Evacuation plans and simulations that model the "expected unexpected" can help evacuation managers mitigate the effect of unforeseen events. A mesoscopic simulation for the evacuation of the Hampton Roads region of southeastern Virginia was created from the macroscopic statewide model (3). The simulation includes the modeling of accidents and incidents with the historical frequencies, severities, and locations. Volume-induced and accident- and incidentinduced queues and associated delays are represented. A previous survey of potential evacuees reported their anticipated route choice decisions when faced with congestion and provided alternative route information and also a mathematical decision-making model representing those decisions (4). This paper reports the integration and testing of the simulation and decision-making (D-M) model, an integration that allows forecasting the effects on a hurricane evacuation of route changes promulgated and made during the evacuation. The effect of an advanced traveler information system (ATIS) was assessed by comparing queue sizes and durations on road segments with injected lane closures both with and without the provision of alternate route information. The integration of a stated-preferencebased route choice model and a dynamic evacuation transportation simulation provides a unique method of forecasting ATIS effectiveness and provides a tool of interest and value to emergency management and transportation professionals.

\section{LITERATURE REVIEW}

The transportation literature is replete with reports on hurricane evacuations and hurricane evacuation simulations. A small sampling of these is provided in the following section, including a few that report on ATIS influence and effectiveness.

Murray-Tuite and Mahmassani used microscopic-level trip chain simulations and linear programming to predict delays and traffic densities occurring before an evacuation begins, primarily as households travel within home regions to gather all members before leaving $(5,6)$.

Theodoulou and Wolshon used the microscopic traffic simulation CORSIM to create a model evaluating the planned use of contraflow in a hurricane evacuation from New Orleans, Louisiana (7). Like Hampton Roads, New Orleans has a large population, few evacuation routes, a very high number of water crossings, and low surface elevation above sea level.

Williams et al. developed a simulation of contraflow operations planned for evacuations from coastal North Carolina in the event 
of high Category 2 or stronger storms (8). The simulation identified the potential for extensive queues at the start and termination of contraflow and was used to identify and test proposed plan modifications.

Robinson (3) reported results of a hurricane evacuation simulation project using mesoscopic simulations to forecast evacuation times and the delays incurred when exit routes were compromised by accidents and incidents, an aspect addressed in greater detail in Robinson et al. (9). The reports showed that during a simulated evacuation from Hampton Roads, when noncatastrophic accidents and incidents were modeled (with total road closures never exceeding $6 \mathrm{~h}$ and no more than one route completely blocked at a time), the introduction consistently increased the total time necessary for evacuees to clear the region by less than $10 \%$. Although individual travel times for vehicles directly blocked by congestion increased, other vehicles were able to shift to alternate paths and when congestion cleared, affected vehicles had essentially clear roads on which to complete their trips.

Robinson et al. identified variables associated with the decision to alter routes and proposed a D-M model for use in a dynamic traffic simulation as a means for evacuation decision makers to assess the effects of driver decisions (9). The relative influence of information sources, including radio, variable message signs, and on-scene state police, was compared as were four levels of information content, including no information, alternate route information only, alternate route information with available services, and on-scene guidance from state police.

Dixit and Radwan examined congestion that occurs during evacuations as a result of a large number of evacuating vehicles overloading the limited capacity of exit ramps offloading traffic onto the heavily loaded network of a destination city (10). Using microscopic modeling, they showed how exit ramp capacities could be the cause of extended travel times.

Kang et al. compared the actions taken by hurricane evacuees for Hurricane Lili with the actions the same evacuees said they expected to take when surveyed 2 years earlier (11). Comparisons were made of expected and actual use of information sources in evacuation decisions, anticipated and actual evacuation preparation time requirements, and expected and actual transportation logistics (mode choice, route choice, number of vehicles, destination, etc.).

Dow and Cutter highlighted the importance of transportation issues in coastal evacuations as traffic problems grow and influence decisions to evacuate (12). They also identified ways that evacuees for Floyd failed to fully use available resources.

Two reports by Wolshon et al. provide a digest of procedures used in several states and localities. The first reviews aspects of planning, preparedness, and response, including decision making in different states, specific planning considerations, and a brief introduction to evacuation modeling (13). The second shifts the focus to evacuation traffic and addresses particular issues involving intelligent transportation systems (14).

Al-Deek et al. developed a framework for evaluating the effect of ATIS by using a composite traffic assignment model that combined a probabilistic traveler behavior model for route diversion with a queuing model under incident conditions (15). The study used a simplified corridor with one alternate route and no access considerations in a simulation as a test platform. Fu and Wilmot expanded work in this area with the development of two dynamic travel demand models for hurricane evacuation by using survival analysis (16).

Prater et al. examined the distribution of information during 1999's Hurricane Bret, including how information was promulgated before and during the storm (17). Differences in the way that residents used various information sources in the evacuation decision were noted. Prater suggested that evacuation managers work closely with local radio stations to improve reporting on evacuation traffic conditions.

Khattak et al. sought a better understanding of drivers' en route decision making in response to traffic delays as a contribution to efforts seeking to reduce traffic congestion (18). The work identified several key factors influencing the likelihood of drivers diverting. It also showed that real-time traffic information broadcasts provided a basis for en route diversion decisions and suggested that the effectiveness of radio broadcasts would increase with information about delay lengths and traffic conditions on alternate routes. In a subsequent study extending this work, Khattak et al. investigated how people deal with unexpected congestion during the pretrip stage and their responses to ATIS (19). The study found that a lack of experience with alternate routes was a critical factor in travelers' willingness to divert and suggested that real-time information on alternatives would encourage diversions.

Pel et al. used the macroscopic evacuation traffic simulation model EVAQ to assess the effect of route change decisions made in an evacuation from Rotterdam, Netherlands. (20). The project assumed that sufficient warning time was provided to conduct the evacuation before the occurrence of the hazard, negating the need to consider network degradation caused by the hazard. EVAQ allows simulating the provision of route decisions to travelers during the evacuation, and that capability was used.

These previous studies are illustrative of a focus on actions and decisions preceding an evacuation's start or on evaluating the adequacy of existing evacuation plans under planned conditions. None focus on assessing, much less forecasting via simulations, the influence of ATIS on evacuation plans. This study concentrates on the period in which evacuees faced with congestion must make decisions to alter or to remain on initial routes and assesses the effect of decisions made on the overall evacuation. Also, the study adapts a statewide macromodel to the mesoscale, allowing the finer detail needed to capture queues at bottlenecks and answer the research questions.

\section{METHODOLOGY}

This project modeled hurricane evacuations from the Hampton Roads region of Virginia by using a modified version of the simulation described in Robinson (3). The previous work allowed user selections of modeled storm strengths (Saffir-Simpson scale 1 to 4), advance notice times, level of accidents and incidents (with default values of 1,400 accidents or incidents during an evacuation), use of contraflow lanes, and whether evacuation of tourists was necessary. Multiple response rates were used during each simulation run. Rates were assigned according to housing type (permanent dwelling, mobile home, or hotel), housing susceptibility to flooding (using flood zone maps), and storm strength.

The simulation was adapted from the statewide macroscopic model, which included 109,054 nodes and 136,561 links. The 2,060 traffic analysis zones in the state model were reduced to 582 for the evacuation model because lesser detail was acceptable outside the Hampton Roads area. The number of vehicles simulated in each run averaged approximately 750,000 . The regional travel demand model included more than 1,500 zones, 15,600 links, and 600 nodes. Evacuees' destinations and response (initiation) rates were based on those suggested for use in evacuation models from Hampton Roads by Baker 
(21). Three response rates were suggested: fast, medium, and slow. No mass evacuations from Hampton Roads have ever been conducted, and only a small portion of the total population in the area has left in advance of previous hurricanes. It is possible that if one hurricane made landfall soon after another, the number of evacuees would significantly increase, much as was seen when Hurricane Rita followed Hurricane Katrina in 2004. The rapid response rate suggested by Baker most closely models this type of response and places the greatest demands on the transportation network. For that reason, the rapid response rate was used. Evacuees were loaded onto the network by using a logit-based rate in which the probability of evacuating by time " $t$ " is determined by

$$
p(t)=1 /\left[1+\delta e^{-\alpha t}\right]
$$

where

$\delta=$ set according to the number of evacuees leaving in advance of an order (equal to nine for the $10 \%$ of evacuees leaving here),

$\alpha=$ the rapidity of evacuation, and

$t=$ time (minutes). The value of $\alpha$ equals $6.549 * 10^{-3}$ for tests using the rapid response rate. This value resulted in an evacuation half-life of $5.6 \mathrm{~h}$.

Robinson and Khattak used data from a behavioral survey of more than 800 potential evacuees to gather information on potential evacuees, their use of traffic information, and its potential influence (4). The survey identified the information types and sources most frequently used by potential hurricane evacuees and their likelihood of diverting when confronted with congestion during an evacuation and provided with information on traffic congestion and alternate routes at different times during an evacuation. This information was used to create a dynamic decision-making model representing the rates at which evacuees are expected to divert from an original to an alternate route. The region's plan uses six primary evacuation routes, two of which were used to assess ATIS influence by integrating the D-M model in the simulation.

Vehicles were consolidated into 10 -vehicle packets and dynamically loaded onto the network in the mesoscopic simulation. The simulation used, Citilabs Cube Avenue, assigns vehicles' routes by using the user-definable variable COST and dynamic traffic assignment. Iterations were not, however, run until true equilibrium was reached because real evacuees are expected to stick to designated evacuation routes, not divert to side roads. The default COST value equals the sum of all link travel times on available routes from a vehicle packet's current position to the end destination. For all available routes to the destination, the length of each road link, the anticipated packet speed, and any delays caused by existing volumes on links are assessed. When high volumes on links of a route result in longer trip times, the COST for that route rises. Packets move forward along the route with the lowest COST (reversing direction to a route already passed is not possible). Packets were influenced to remain on designated evacuation routes by applying a multiplying factor (called COSTFACTOR) to nonevacuation route COST calculations, raising the COST values.

\section{Congestion Test Events}

Integration of the D-M model into the simulation used two congestion test events (CTEs). CTEs simulated the complete closure of one travel lane for $1 \mathrm{~h}$ by reducing road capacities. Each CTE was placed on a section of roadway with two lanes in each direction, and by using the guidance of the Highway Capacity Manual (2000), capacities were reduced to $35 \%$ for the 1-h duration (22). One CTE was placed on an Interstate (I-64) segment and one on a state highway (US-460). Each CTE was placed to allow vehicles to alter paths to a roughly parallel road until the congested portion of the primary route was bypassed, and either the original route was rejoined or the next leg of the evacuation trip was reached.

\section{Interstate Congestion Test Event}

The Interstate CTE was placed just before I-64 Exit 227 (VA-30). Figure 1 shows this location, the alternate route on US-60, and access road connections. The Interstate CTE location allowed multiple accesses to the alternate route. The combined hourly capacities of the accesses and of the Interstate alternate route, US-60, were greater than the maximum expected rate of vehicles that were expected to divert to the alternate route at any time. The first upstream exit point was 2 mi distant, and congestion was required to extend without D-M model integration. When the D-M model was used to simulate ATIS contributions, vehicles diverted to the alternate route (US-60) at Exits 231, 234, 242, or 243. Capacities on roads used to access US-60 are shown in the figure. The number of available access points and the combined capacities of the access road segments (greater than 4,900 vehicles per hour) increased the likelihood that vehicles had the opportunity to divert.

Diverting traffic rejoined I-64 at Exits 227 or 205 or remained on US-60 until reaching I-295, 1 mi south of the I-64/I-295 interchange. Dependent on the access and exit points, alternate route length varied between approximately 4 and $40 \mathrm{mi}$.

\section{Highway Congestion Test Event}

The CTE on US-460 was approximately 3 mi northwest of Windsor, Virginia. Figure 2 shows the US-460 section, alternate route, access routes, and capacities. As at the Interstate CTE, multiple accesses were available, but combined access route capacities and alternate route capacity were less than the maximum expected volume of diverting traffic. The alternate route bypassed the CTE on US-460 by using SR-638. It could be accessed either 1.0 or $2.5 \mathrm{mi}$ southeast of the CTE. All traffic on the alternate route rejoined US-460 less than $1 / 4 \mathrm{mi}$ northwest of the CTE; no other routes are available. Alternate route length was either 3.6 or $6.7 \mathrm{mi}$, and it bypassed either 2.1 or $4.6 \mathrm{mi}$ on US-460.

\section{Decision-Making Model Integration}

The effects of the D-M model were added to the simulation by using a second multiplying factor (called "DECISION") to COST calculation along the evacuation route section affected by the simulated congestion at the CTE. This temporary increase in COST had the effect of making alternate routes' COST lower and thus more attractive in route assignment. DECISION was set to a value greater than COSTFACTOR, prompting appropriate evacuees to divert. DECISION was gradually reduced as the primary evacuation route cleared, and congestion began to cause delays on the alternate route. Without reducing the value of DECISION, vehicles would remain 


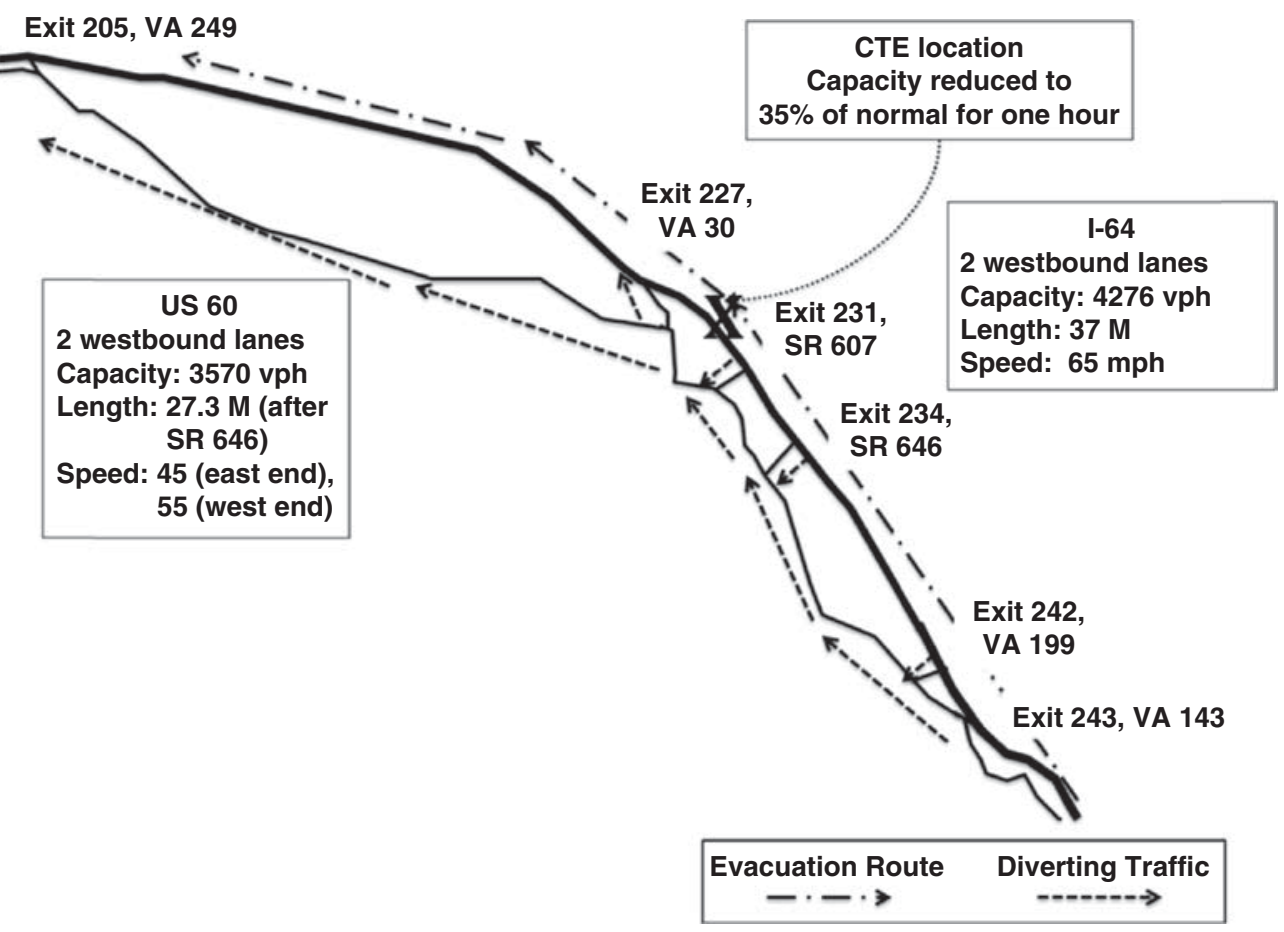

FIGURE 1 I-64 congestion test event location and connections to Alternate Route US-60.

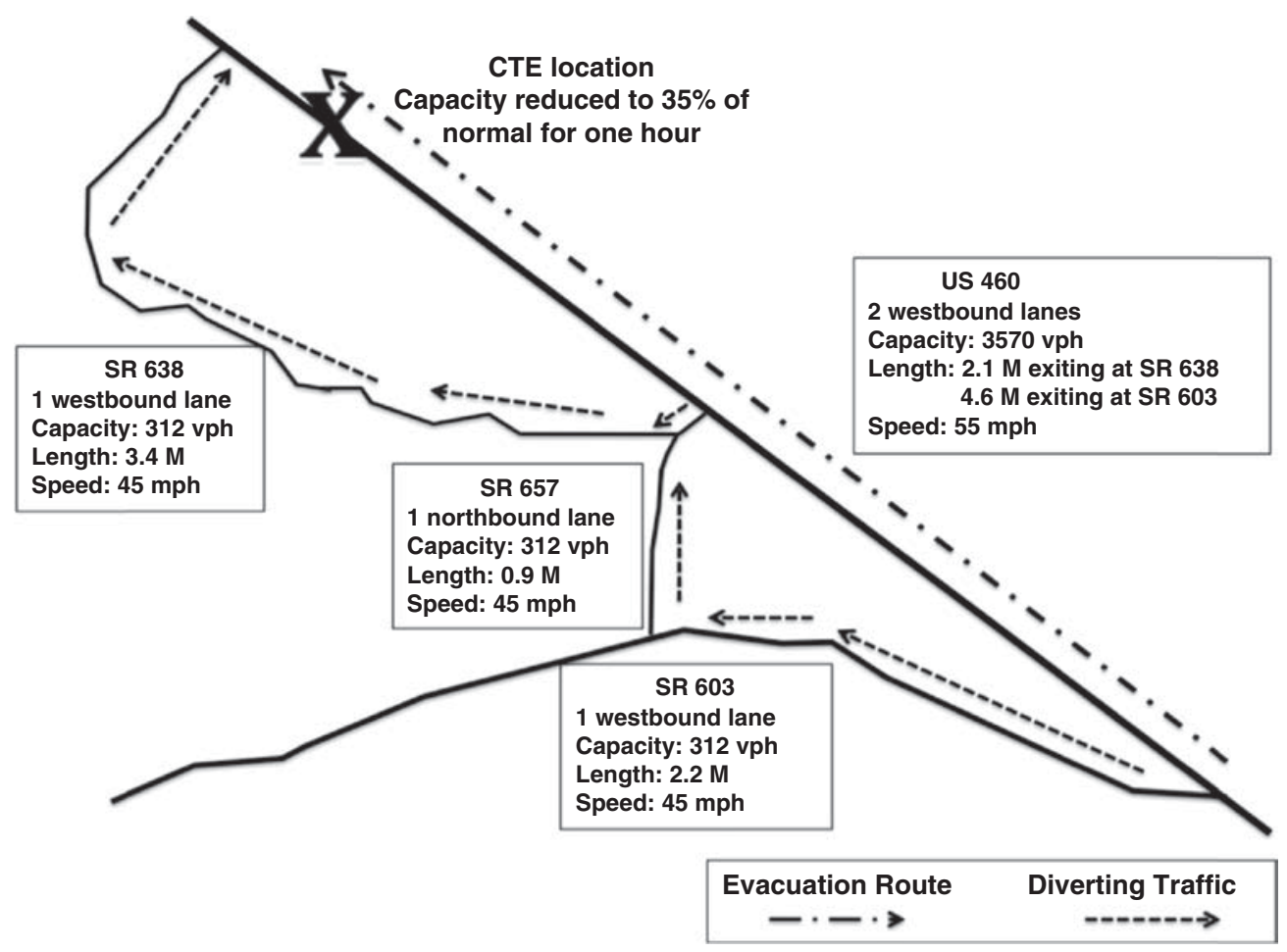

FIGURE 2 US-460 congestion test event location and connections to Alternate Route SR-638. 


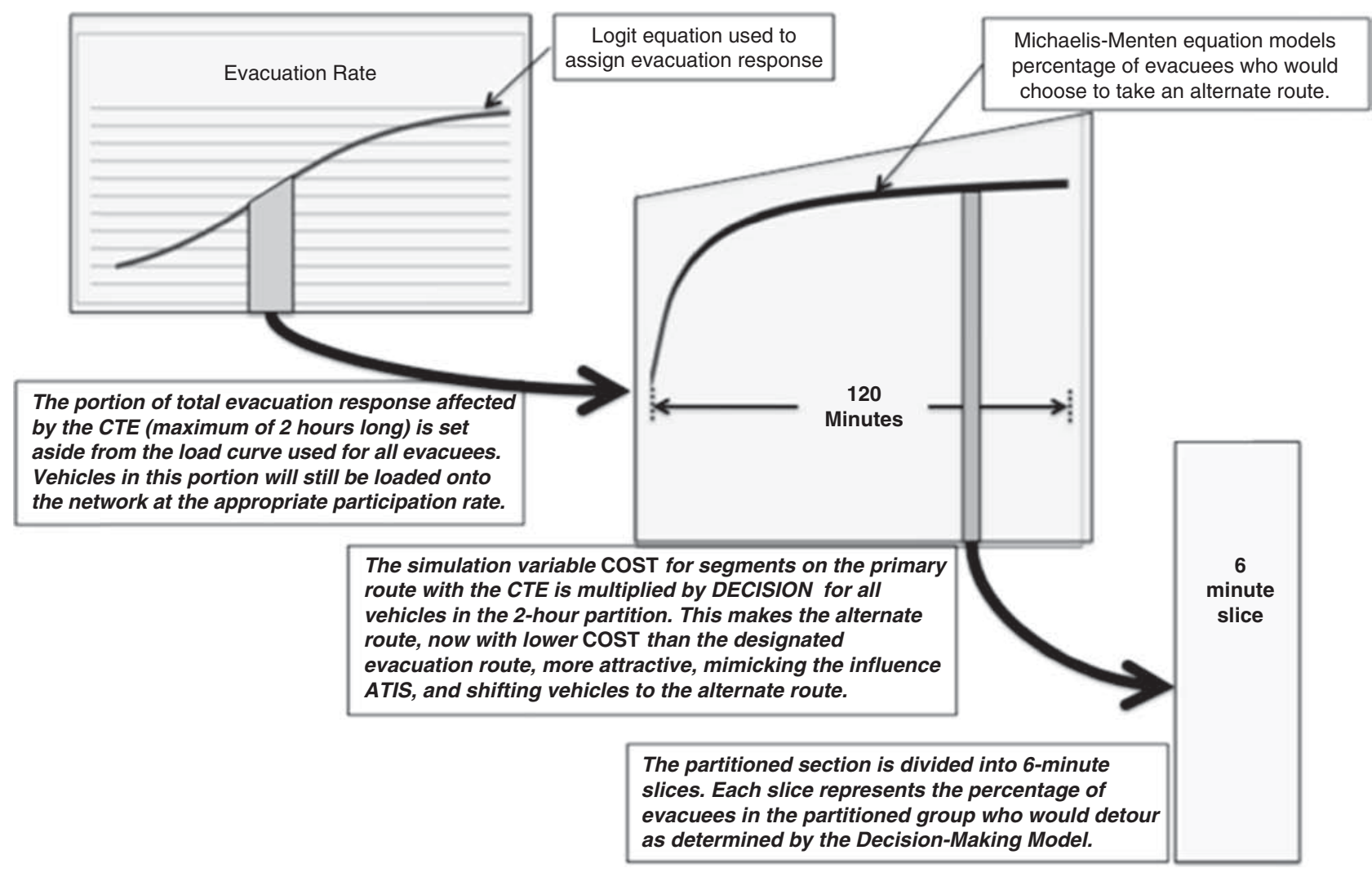

FIGURE 3 Influencing evacuating vehicles to detour using the decision-making model.

on alternate routes even after the primary route was cleared. This mimicked the shifts of evacuees between routes to minimize travel times. This method allowed vehicles to adjust routes to reduce trip times without affecting the rest of the network by changing the value of COSTFACTOR. The process is illustrated in Figure 3 and explained below:

1. The overall evacuation rate was modeled by using a sigmoidshaped logit equation; a rate common to evacuation response is shown in the left-most graph of Figure 3. Start times varied by geographic area, with those at greatest risk from the storm leaving first.

2. The next step required determining, for each assignment matrix, which packets left their origins and arrived at the CTE location while congestion was present. This was required to ensure that the D-M model was applied to the correct evacuating vehicles. The shaded area under the evacuation curve shows the time period those packets left.

3. The D-M model modeled the percentage of evacuees who indicated they would use an alternate route at different time interval points after encountering congestion when provided with specific ATIS information via different sources. The D-M model was applied only to those packets in each assignment matrix represented by the shaded area. The decision-model curve for one scenario is shown in the middle graph of Figure 3. The left value of this curve is at 34\%, representing the members of the sample population who indicated they would divert when congestion was first confronted, even without ATIS.

4. The simulation was run with a 6-min update rate during testing, and evacuation rate and D-M were applied to each 6-min section. This is shown by the right-most graph in Figure 3.
Vehicles beginning travel before or after the selected group have COST variables assigned that bias remaining on the designated route and use the alternate route only if calculated COST values (using the multiplying factor COSTFACTOR) are less on the alternate route.

\section{ANALYSIS}

Simulation runs were completed for each CTE with and without traffic information influence modeled with the D-M model. Each information type previously noted was modeled individually and in combination with other types. Four sets of data were recorded to assess the effect of route choices:

1. Queue duration due to the incident (minutes),

2. Queue size (number of vehicles),

3. Total number of packets reaching the next leg of the primary route downstream of the $\mathrm{CTE}$, and

4. Number of packets using the alternate route.

Before tests were begun, steady-state conditions were established with primary evacuation routes at or near maximum volume by running the simulation for approximately 6 (simulated) hours. CTEs were then inserted for $1 \mathrm{~h}$, with primary route capacity reduced to $35 \%$ of normal. Volume and queue measurements were recorded for alternate and primary routes for $3 \mathrm{~h}$. More than 1,100 runs were completed. Each required approximately $75 \mathrm{~min}$ of dedicated computer processing time using HP xw4400 Workstation computers with 
TABLE 1 Interstate Test Results: Evacuating Traffic Volumes and Queue Durations Without and With Decision-Making Model Integration Simulating ATIS

\begin{tabular}{|c|c|c|c|c|c|c|c|c|c|}
\hline I-64 Results & Measurement & $\begin{array}{l}\text { Total } \\
\text { Vehicles on } \\
\text { Alternate } \\
\text { Route }\end{array}$ & $\begin{array}{l}\% \text { Increase } \\
\text { (over no } \\
\text { D-M case) }\end{array}$ & $\begin{array}{l}\text { Total } \\
\text { Vehicles } \\
\text { on I-64 }\end{array}$ & $\begin{array}{l}\text { \% Increase } \\
\text { (over no } \\
\text { D-M case) }\end{array}$ & $\begin{array}{l}\text { Vehicles } \\
\text { on Route } \\
\text { Exiting } \\
\text { Region }\end{array}$ & $\begin{array}{l}\% \text { Increase } \\
\text { (over no } \\
\text { D-M case) }\end{array}$ & $\begin{array}{l}\text { Maximum } \\
\text { Queue } \\
\text { Duration } \\
\text { (min) }\end{array}$ & $\begin{array}{l}\% \text { Increase } \\
\text { (over no } \\
\text { D-M case) }\end{array}$ \\
\hline No CTE (max flow) & Average & 0 & na & $12,341.8$ & na & $12,341.8$ & na & 48 & na \\
\hline No D-M simulation & $\begin{array}{l}\text { Average } \\
\text { SD }\end{array}$ & $\begin{array}{r}741.2 \\
17.5\end{array}$ & - & $\begin{array}{r}11,882.8 \\
40.9\end{array}$ & - & $\begin{array}{r}12,066.5 \\
40.5\end{array}$ & - & $\begin{array}{r}165.8 \\
11.4\end{array}$ & - \\
\hline $\begin{array}{l}\text { Average of } 4 \text { scenarios } \\
\text { with D-M Simulation }\end{array}$ & $\begin{array}{l}\text { Average } \\
\text { SD }\end{array}$ & $\begin{array}{r}4,444.3 \\
51.4\end{array}$ & $\begin{array}{r}499.6 \\
-\end{array}$ & $\begin{array}{r}8,690.7 \\
333.6\end{array}$ & $\begin{array}{r}-26.9 \\
-\end{array}$ & $\begin{array}{r}12,733.9 \\
305.6\end{array}$ & 4.7 & $\begin{array}{r}86.8 \\
4.4\end{array}$ & $\begin{array}{r}47.6 \\
-\end{array}$ \\
\hline
\end{tabular}

Note: na $=$ not applicable $;-=$ no data to compare in this simulation; $\mathrm{SD}=$ standard deviation; $N=41$; simulated time period postincident $=3.3 \mathrm{~h}$.

TABLE 2 U.S. Highway Test Results: Evacuating Traffic Volumes and Queue Durations Without and With Decision-Making Model Integration Simulating ATIS

\begin{tabular}{|c|c|c|c|c|c|c|c|c|c|}
\hline US-460 Results & Measurement & $\begin{array}{l}\text { Total } \\
\text { Vehicles on } \\
\text { Alternate } \\
\text { Route }\end{array}$ & $\begin{array}{l}\% \text { Increase } \\
\text { (over no } \\
\text { D-M case) }\end{array}$ & $\begin{array}{l}\text { Total } \\
\text { Vehicles } \\
\text { on US-460 }\end{array}$ & $\begin{array}{l}\text { \% Increase } \\
\text { (over no } \\
\text { D-M case) }\end{array}$ & $\begin{array}{l}\text { Vehicles } \\
\text { on Route } \\
\text { Exiting } \\
\text { Region }\end{array}$ & $\begin{array}{l}\% \text { Increase } \\
\text { (over no } \\
\text { D-M case) }\end{array}$ & $\begin{array}{l}\text { Maximum } \\
\text { Queue } \\
\text { Duration } \\
\text { (min) }\end{array}$ & $\begin{array}{l}\% \text { Increase } \\
\text { (over no } \\
\text { D-M case) }\end{array}$ \\
\hline No CTE (max flow) & Average & 0 & na & $9,708.1$ & na & $9,708.1$ & na & 6 & na \\
\hline No D-M simulation & $\begin{array}{l}\text { Average } \\
\text { SD }\end{array}$ & $\begin{array}{l}528.7 \\
146.8\end{array}$ & - & $\begin{array}{r}8,901.0 \\
678.8\end{array}$ & - & $\begin{array}{r}9,429.7 \\
756.7\end{array}$ & - & $\begin{array}{r}194.8 \\
14.5\end{array}$ & - \\
\hline $\begin{array}{l}\text { Average of } 4 \text { scenarios } \\
\text { with D-M Simulation }\end{array}$ & $\begin{array}{l}\text { Average } \\
\text { SD }\end{array}$ & $\begin{array}{r}1,255.17 \\
215.80\end{array}$ & $\begin{array}{r}137.6 \\
-\end{array}$ & $\begin{array}{r}8,148.6 \\
912.3\end{array}$ & -8.5 & $\begin{array}{r}9,403.71 \\
972.47\end{array}$ & -0.3 & $\begin{array}{r}190.1 \\
22.0\end{array}$ & $\begin{array}{r}2.4 \\
-\end{array}$ \\
\hline
\end{tabular}

Note: $\mathrm{na}=$ not applicable $;-=$ no data to compare in this simulation; $N=41$; simulated time period postincident $=3.3 \mathrm{~h}$.

the Windows XP operating system and equipped with Intel Core2 Quad 2.66-GHz processors and 3.2-GB memory.

Table 1 provides the evacuating traffic volumes and queue durations for the Interstate test. Table 2 provide those data for the U.S. highway tests. Results are provided for evacuations with no deliberately induced congestion (no CTE), with induced congestion but no simulated ATIS and D-M model influence (no D-M simulation), and averaged results for four ATIS scenarios (assessing 164 runs).

\section{Interstate Congestion Test Event Analysis}

Figure 4 shows a screen capture from one test set along the I-64 CTE segment. The upper graphic shows the traffic queue building up to the east (right) of the road segment where the incident occurred. A limited amount of traffic, representative of the sample population respondents who anticipated diverting even without traffic information, is on the alternate route. Some traffic (35\%) passed through the restricted segment. When the D-M was not integrated, vehicles began diverting to US-60 within four to five time segments (24-30 min) at Exit 231 (SR-607). However, the queue quickly restricted access to the I-64 exit, preventing many vehicles from diverting to the alternate route. Congestion continued to extend to the next access at Exit 234 (SR-646), which became the primary alternate route access without D-M model integration. Queues caused by the incident lasted for an average of $196 \mathrm{~min}$.

The lower graphic shows the same scenario, but with D-M model integration modeling included to assess the effect of traffic information. Queue growth was slower with the D-M model, and many more packets diverted to the alternate route. Vehicles began to divert to the alternate route at Exit 243 by using VA-143, approximately $16 \mathrm{mi}$ upstream of the incident. Additional shifts to the alternate route were made at the remaining three exits, but VA-143 remained the primary access to the alternate route for all D-M-influenced simulations. The large number of vehicles exiting well before the congested area is supported by the real-world behavior observed by Levinson and Huo, who used empirical data from loop detector systems to assess drivers' responses to variable message sign information and noted that drivers prefer to start diverting at several exits before the incident (23).

Without D-M model integration, approximately $25 \%$ of all evacuees rejoined I-64 at the first opportunity (Exit 227, VA-30), with most of the rest rejoining I-64 before the intersection with I-295 at Exit 205. With the D-M model, a smaller portion $(<10 \%)$ rejoined at I-64, with most vehicles rejoining at Exit 205 or continuing on the alternate route until reaching the major leg of the evacuation journey at I-295.

Approximately six times more packets used the alternate route when the D-M model was integrated. After the CTE ended on I-64, the queue shrank, with queues on downstream segments clearing first without the D-M model and upstream clearing first with it. This result occurred because without the D-M model, incoming traffic volume to the CTE was slightly greater than outgoing volume, and upstream segments stayed very congested. When the D-M model and high volumes of traffic existed on the alternate route, incoming volume was significantly less than the outflow volume at the head of the queue. Queue duration was more than twice as long when no ATIS was provided (196 min) as when ATIS was provided ( $87 \mathrm{~min}$ ). 


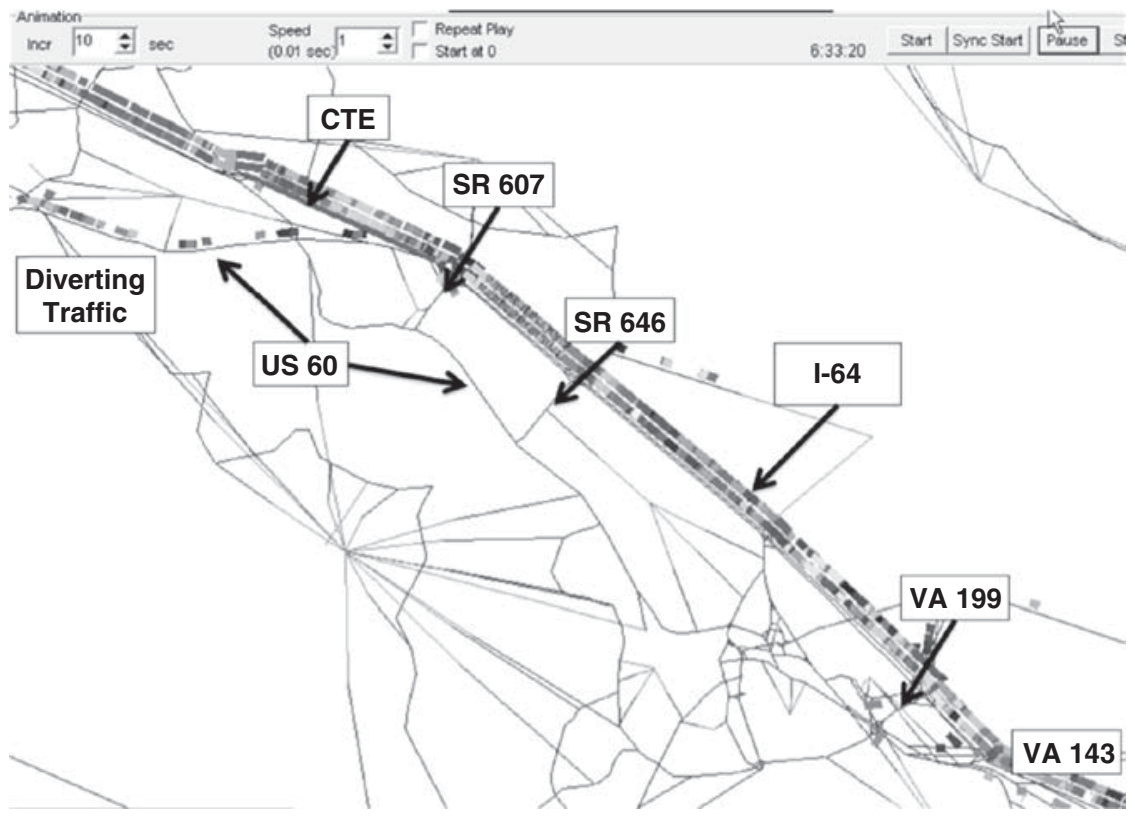

(a)

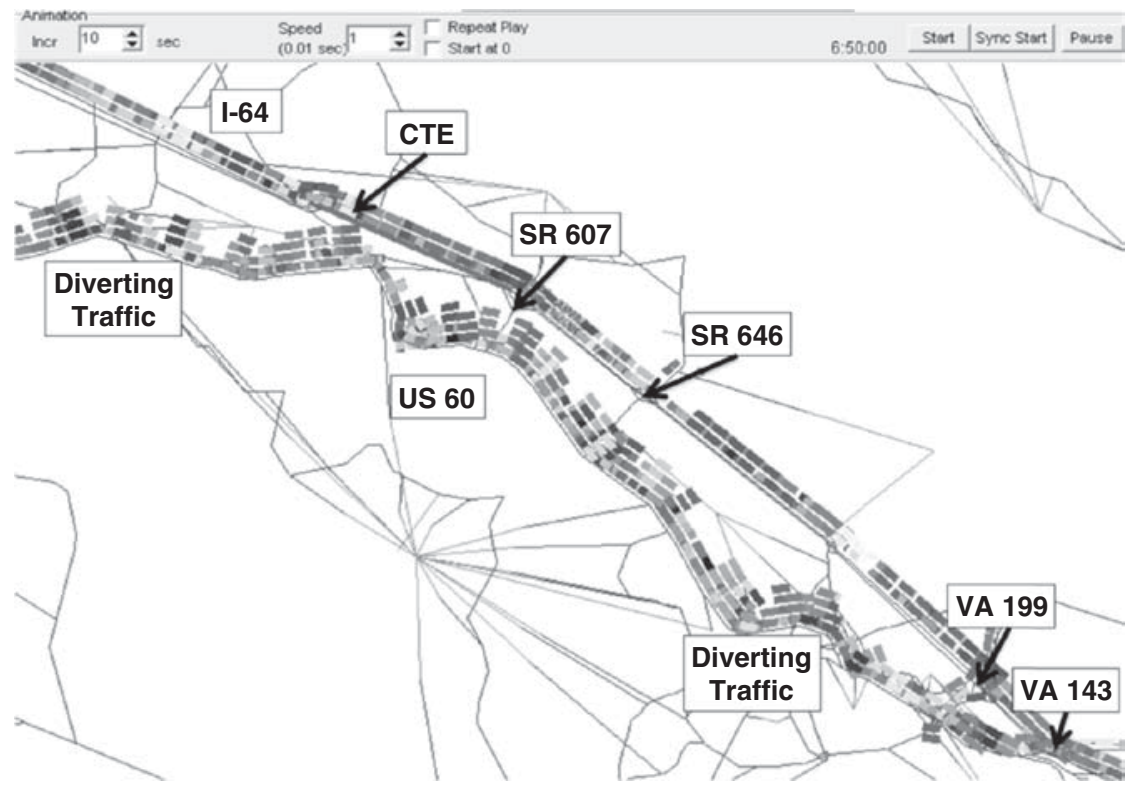

(b)

FIGURE 4 Interstate CTE test screen captures: (a) without decision-making model integration and $(b)$ with decision-making model integration.

\section{Highway Congestion Test Event Analysis}

The queue on US-460 without the D-M model extended to the first upstream exit (SR-638) in just 15 min. Packets attempted to access the alternate route on SR-638, but congestion quickly blocked most from reaching the exit. The relatively few packets able to exit quickly exceeded the low capacity of the alternate route. With the D-M model, some vehicles diverted early at SR-603, rejoining the alternate route via SR-657. However, the limited capacity of these segments, and delays caused by merging traffic, caused additional queuing. As a result, far fewer vehicles than forecast by the sample population actually used the alternate route. D-M model influence more than doubled the alternate route volume, but still just $13 \%$ of evacuees in the test period used the alternate route. The differences in queue clearance times with and without the D-M model scenarios were not statistically significant. Although the D-M model prompted an increase in the number of vehicles on the alternate route, there was no corresponding increase in the number of evacuees reaching the next leg of their journey. In fact, the average number of evacuees with the D-M model was slightly less than without it. Although 
the difference was not statistically significant, the fact that there was no improvement in performance despite simulated ATIS addition and route changes by more than 1,200 vehicles is important. CTE queue duration was an average of $2.5 \%$ (approximately $5 \mathrm{~min}$ ) less when ATIS was provided than without ATIS. Both volume and queue duration data showed much more variance for the US-460 tests than seen on I-64. Whereas I-64 standard deviations differed from averages by $2.5 \%$ to $5 \%$, US-460 differences were $10 \%$ to $12 \%$. The observed variance was a result of the small capacities on the alternate route and its accesses amplifying the effects of even small changes in the arrival times of vehicles with different D-M route choice tendencies.

To summarize, queue duration was the information of most use in the assessments. Queue sizes varied widely depending on the random seed used in traffic assignment, which led to some variance in destinations and the rate at which packets traveled on individual routes. On the Interstate, the combined capacities of the Interstate and alternate route exceeded the load rate upstream of the incident, so as the queue cleared, the number of packets able to reach the next leg was restricted by capacities upstream of the incident. On the highway, the opposite situation prevailed. Queue development was so extensive and the reduction of capacity resulting from merging traffic so extensive that no improvement was seen by the use of the D-M model.

\section{LIMITATIONS}

It is important to note the scope and assumptions of this study:

- The survey and analyses targeted residents in the Hampton Roads region of Virginia. Results should not be directly applied to other areas without further study. However, the Hampton Roads region modeled includes approximately 1.7 million residents and includes urban, suburban, and rural areas. It has more than $600 \mathrm{mi}$ of primary and Interstate roadway and includes almost 1,500 bridges and five tunnels. These characteristics improve the value of the study to other regions.

- Analyses assume that current users of traffic information and its influence are reasonably related to what would be expected in an emergency evacuation scenario.

- Analysis relies on the use and influence of traffic information claimed by the sample population. The information has not been validated by any observed or actually exhibited behavior. In any survey questioning the future intentions of respondents, one must keep in mind that intentions may differ from the actions that are actually taken during an event.

\section{CONCLUSIONS}

This paper contributes by exploring the role of information in nonroutine travel conditions, that is, when people are evacuating a region. The study shows that a decision-making model forecasting evacuees' propensity to choose alternate routes when confronted with congestion can be integrated into a dynamic traffic simulation and demonstrate the effect of anticipated ATIS use in a hypothetical hurricane evacuation. This work is valuable because application of the simulation can provide greater insight to evacuation planners seeking to understand in advance the effect of dynamic route changes and information distribution during an evacuation. The following insights were key to the specific scenarios tested in the project:

- The effectiveness of ATIS was increased if provided early enough to allow route changes well before the evacuation. When vehicles cannot detour until nearing the location of congestion queuing, access to alternate routes may be limited or blocked.

- As shown in the Interstate tests, adding capacity by adding alternate routes can help clear congestion, but total traffic flow may be limited by capacity constraints upstream, something ATIS cannot change. However, by clearing all traffic reaching the test site at a rate essentially equal to that expected with no disruptions, plan stability and reliability may be preserved.

- Evacuees diverting to alternate routes may worsen rather than improve congested situations. In the U.S. highway tests, limited access to and capacity of alternate routes resulted in extensive congestion and queuing when vehicles were encouraged to divert, blocking side roads that might have been used by emergency responders while providing no improvement in the overall evacuation. ATIS could be used to discourage route changes.

Analyses of results show that by directing traffic to alternate routes after an incident, ATIS has the potential to mitigate the effect of congestion on evacuation rates and can also significantly reduce the duration of resulting queues. However, ATIS cannot be considered a "one-size-fits-all solution." Successful sites for using ATIS to improve traffic flow following incident-induced congestion during evacuations require

- Multiple accesses to alternate routes,

- Adequate capacity on alternate routes and their accesses,

- Access routes located well in advance of the incident, and

- ATIS availability.

When any of the first three conditions are not met, evacuees' intentions to use alternate routes may be thwarted by alternate route availability and capacity, and their actions could cause worsening of congestion and travel delays instead of fostering improvement. Without ATIS, drivers will not receive information on alternate routes.

Two test sites were used. The first, located on a major Interstate highway, made use of multiple accesses to an alternate route with capacity equal to $80 \%$ of the capacity of the primary route. The alternate route also provided multiple ways for vehicles to rejoin evacuating traffic. As a result, even though the alternate route was never loaded to capacity, more than one-third of all evacuating traffic made use of it, and queue durations were significantly shortened. Although not tested, rapid queue reductions may also offer the benefit of reducing the effect of secondary incidents. Although there is a statistically significant increase in the number of vehicles reaching the next leg of the journey, the average increase was equivalent to just 6 min of evacuation time. The reason was that there were capacity constraints upstream of the CTE location, where the number of lanes was reduced from three to two. These lanes were at capacity throughout the test period and effectively capped any improvement possible. Thus, on the Interstate section tested, the benefit of using an alternate route was primarily from the significant reduction in incident-induced queuing and gridlock by removing vehicles from the primary evacuation route, and not from a higher evacuation flow rate.

The second test site was on a state highway. Only two accesses to the alternate route were available, and the accesses and the alter- 
nate route itself had significantly lower capacities than the primary route (less than 10\%). Queues formed at the CTE location, at alternate route accesses, at intersections where two access roads met, and at the single location where vehicles using the alternate route could rejoin evacuating traffic. Queues that developed on the alternative routes persisted almost as long as those on the highway itself. As a result, there was no improvement in the flow of evacuating vehicles, and emergency responder access would have been reduced as a result of congestion on all routes. The failure of this site to show an improvement when ATIS was introduced demonstrates the necessity of understanding each situation before resources are invested.

The importance of early identification of congestion and early provision of traffic information to evacuees was seen by varying the time in advance of a CTE that the partition is selected. When alternate route choices were made too late, extensive queue growth blocked alternate route accesses, delayed queue clearance times, and reduced the effectiveness of the evacuation.

\section{ACKNOWLEDGMENTS}

The support provided by the Virginia Modeling, Analysis, and Simulation Center (VMASC) and the Old Dominion University (ODU) Transportation Research Institute is appreciated.

\section{REFERENCES}

1. Hurricane Floyd Assessment. Prepared for U.S. Army Corps of Engineers (Savannah District) and Federal Emergency Management Agency (Region IV) by Post, Buckley, Schuh and Jernigan, Inc., May 2000 .

2. National Oceanic and Atmospheric Administration National Climatic Data Center. Hurricane Rita. http://www.ncdc.noaa.gov/special-reports/ rita.html. Accessed May 19, 2010.

3. Robinson, R. M. Hampton Roads Hurricane Evacuation Study. Report Number V07-008. Provided to and available from the Virginia Department of Emergency Management, Richmond, Va., 2007.

4. Robinson, R. M., and A. Khattak. Route Change Decision Making by Hurricane Evacuees Facing Congestion. In Transportation Research Record: Journal of the Transportation Research Board, No. 2196, Transportation Research Board of the National Academies, Washington, D.C., 2010, pp. 168-175.

5. Murray-Tuite, P. M., and H. S. Mahmassani. Model of Household Trip-Chain Sequencing in Emergency Evacuation. In Transportation Research Record: Journal of the Transportation Research Board, No. 1831, Transportation Research Board of the National Academies, Washington, D.C., 2003, pp. 21-29.

6. Murray-Tuite, P. M., and H. S. Mahmassani. Transportation Network Evacuation Planning with Household Activity Interactions. In Transportation Research Record: Journal of the Transportation Research Board, No. 1894, Transportation Research Board of the National Academies, Washington, D.C., 2004, pp. 150-159.

7. Theodoulou, G., and B. Wolshon. Alternative Methods to Increase the Effectiveness of Freeway Contraflow Evacuation. In Transportation Research Record: Journal of the Transportation Research Board, No. 1865, Transportation Research Board of the National Academies, Washington, D.C., 2004, pp. 48-56.
8. Williams, B. M., A. P. Tagliaferri, S. S. Meinhold, J. H. Hummer, and N. M. Rouphail. Simulation and Analysis of Freeway Lane Reversal for Coastal Hurricane Evacuation. Journal of Urban Planning and Development, Vol. 133, No. 1, 2007, p. 61-72.

9. Robinson, R. M., A. Khattak, J. Sokolowski, P. Foytik, and X. Wang. What Is the Role of Traffic Incidents in Hampton Roads Hurricane Evacuations? Presented at 88th Annual Meeting of the Transportation Research Board, Washington, D.C., 2009.

10. Dixit, V. V., and E. A. Radwan. Strategies to Improve Dissipation into Destination Networks Using Macroscopic Network Flow Models In Transportation Research Circular E-C149: 75 Years of the Fundamental Diagram for Traffic Flow Theory: Greenshields Symposium, Transportation Research Board of the National Academies, Washington, D.C., 2011, pp. 216-235.

11. Kang, J. E., M. K. Lindell, and C. S. Prater. Hurricane Evacuation Expectations and Actual Behavior in Hurricane Lili. Journal of Applied Social Psychology, Vol. 37, No. 4, 2007, pp. 887-903.

12. Dow, K., and S. L. Cutter. Public Orders and Personal Opinions: Household Strategies for Hurricane Risk Assessment. Environmental Hazards, Vol. 2, 2000, pp. 143-155.

13. Wolshon, B., E. Urbina, C. Wilmot, and M. Levitan. Review of Policies and Procedures for Hurricane Evacuation. I: Transportation Planning, Preparedness, and Response. Natural Hazards Review, Vol. 6, No. 3, 2005, pp. 129-142.

14. Wolshon, B., E. U. Hamilton, M. Levitan, and C. Wilmot. Review of Policies and Practices for Hurricane Evacuation. II: Traffic Operations, Management, and Control. Natural Hazards Review, Vol. 6, No. 3, 2005, pp. 143-161.

15. Al-Deek, H. M., A. J. Khattak, and P. Thananjeyan. A Combined Traveler Behavior and System Performance Model with Advanced Traveler Information Systems. Transportation Research Part A, Vol. 32, No. 7 1998, pp. 479-493.

16. Fu, H., and C. G. Wilmot. Survival Analysis-Based Dynamic Travel Demand Models for Hurricane Evacuation. In Transportation Research Record: Journal of the Transportation Research Board, No. 1964, Transportation Research Board of the National Academies, Washington, D.C., 2006, pp. 211-218.

17. Prater, C. S., D. Wenger, and K. Grady. Hurricane Bret Post Storm Assessment: A Review of the Utilization of Hurricane Evacuation Studies and Information Dissemination. Hazard Reduction and Recovery Center, Texas A\&M University, College Station. 2000. http://archone.tamu.edu/ hrrc/Publications/researchreports/index.html. Accessed June 16, 2009.

18. Khattak, A. J., J. L. Schofer, F. S. Koppelman, and R. D. Huchingson Factors Influencing Commuters' En Route Diversion Behavior in Response to Delay. In Transportation Research Record 1318, TRB, National Research Council, Washington, D.C., 1991, pp. 125-135.

19. Khattak, A., A. Polydoropoulou, and M. Ben-Akiva. Modeling Revealed and Stated Pretrip Travel Response to Advanced Traveler Information Systems. In Transportation Research Record 1537, TRB, National Research Council, Washington, D.C., 1996, pp. 46-54.

20. Pel, A. J., S. P. Hoogendoorn, and M. C. J. Bliemer. Impact of Variations in Travel Demand and Network Supply Factors for Evacuation Studies. In Transportation Research Record: Journal of the Transportation Research Board, No. 2196, Transportation Research Board of the National Academies, Washington, D.C., 2010, pp. 45-55.

21. Baker, E. J. Virginia Hurricane Evacuation Behavioral Survey and Analysis. Unpublished. Prepared for the U.S. Army Corps of Engineers, Norfolk District. Available from the Virginia Department of Emergency Management, Richmond, May 2007.

22. Highway Capacity Manual. TRB, National Research Council, Washington, D.C., 2000

23. Levinson, D., and H. Huo. Effectiveness of VMS Using Empirical Loop Detector Data. Presented at 82nd Annual Meeting of the Transportation Research Board, Washington, D.C., 2003.

The Transportation Safety Management Committee peer-reviewed this paper 